\title{
SOBRE HERANÇA E SINGULARIDADE: O COMPLEXO DE ÉDIPO E DON JUAN
}

Virginia Helena Ferreira da Costa

Universidade de São Paulo - USP. Doutoranda no Departamento de Filosofia.

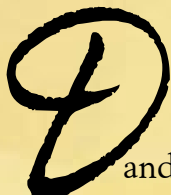
temática do donjuanismo junto à leitura psicanalítica, propomos uma articulação entre textos da literatura e conceitos psicanalíticos freudianos, trazendo uma confrontação da teoria do complexo de Édipo e da peça de Don Juan (versão de Molière). O objetivo principal de nosso texto é tratar do tema da herança geracional a partir da filogênese e a teoria social freudianas, como mecanismos que tornam a lei edípica geral e inescapável. Don Juan aparece como contraponto à filiação familiar e cultural: modelo do sedutor que nega as determinações sociais ligadas aos imperativos de seu pai. Ele representa uma possibilidade de trazer à tona o debate sobre a constituição singular de uma trajetória de vida ligada à realização de desejos relativamente a seus objetos de amor, motivo que nos leva a questionamentos sobre as noções de pertencimento, reconhecimento, transgressão e autonomia, além da ausência de culpa. É neste âmbito que faremos também um paralelo entre o mítico banquete encontrado em "Totem e tabu" e o jantar de morte de Don Juan com a estátua do Comendador, cujo fantasma levará o sedutor para o Além. Ultrapassando as especificidades que tais banquetes signifiquem em seus contextos, exporemos como se trata de um fundo comum, a saber, da repetição da lei que se faz necessária por meio de uma espécie de "transcendência" do fantasma que determina as trajetórias singulares, repetição esta ligada à noção de pulsão de morte freudiana.

Palavras-chave: Lei. Édipo. Herança. Singularidade. Fantasma. 
A relação entre a figura literária de Don Juan e a teoria psicanalítica é frequente na história das ideias. Afinal, o personagem que seduz, trazendo fascínio e desconfiança é considerado um ícone na abordagem sobre a perversão, servindo também como mote para uma análise histórica do rompimento do Antigo Regime, na medida em que Don Juan quebra os valores vigentes de honra e fé católica.

Desde a criação do primeiro Don Juan por Tirso de Molina em 1617 até a versão de Byron em 1819, passando por Don Giovanni de Mozart de 1787, o tipo característico do Don Juan permanece o mesmo: ele é um conquistador que, com sua irresistível lábia, confunde os personagens com quem contracena, ao prometer se casar com donzelas, pagar dívidas, seguir a lei e os costumes valorizados pela sociedade. No entanto, na versão que mais nos interessa, aquela de Molière, de 1665, o sedutor acaba assassinando o personagem portador da Lei, o Comendador. Logo após este assassinato, Don Juan vai até a estátua de sua vítima para um banquete, uma vez que o espírito do Comendador o convidou a cear em sua lápide. No momento do banquete, no entanto, Don Juan é levado à morte pelo espírito de sua vítima.

É notando as especificidades da versão de Molière - a saber, o assassinato do portador da lei, a presença do espectro desta vítima e a ocasião do banquete - que propomos um comentário que não irá tratar de uma análise histórica, nem mesmo do tema da perversão. Diferentemente, pretendemos construir uma outra análise que porta sobre a exceção à lei, lei esta entendida como herança filogenética generalizada a partir do complexo de Édipo freudiano. Assim, a figura de Don Juan será usada como contraponto a uma filiação familiar e cultural, culminando na formação de uma singularidade subjetiva que escapa a esta determinação social imperativa. Apesar de tal análise se aproximar do conceito de perversão, lembramos que nossa leitura privilegia a abordagem de aspectos morais em relação ao tema pulsional e sexual do perverso.

Para tanto, tratemos inicialmente da generalidade assumida pelo complexo de Édipo na teoria freudiana, fase de desenvolvimento infantil vivenciada de forma necessária por todos os indivíduos. A pesquisa freudiana encontrou uma similitude arquetípica entre os domínios individual e coletivo: a descoberta de Freud segundo a qual a trama do Édipo seria um elementobase da cultura humana forneceu, a este complexo, contornos generalizantes. Nesse âmbito, um dos primeiros momentos em 


\section{aldenos

que Freud trata do complexo de Édipo como geral pode ser conferido na carta de 15 de outubro de 1897 enviada a Fliess. Citemos Freud:

Veio-me ao espírito uma ideia que tem um valor geral
(von allgemeinem $W e r t$ ). Eu achei igualmente em mim
o movimento amoroso em direção à mãe e o ciúme
diante do pai e eu os considero atualmente como um
acontecimento geral (ein allgemeines Ereignis) a todas
as jovens crianças. (FREUD apud SCHNEIDER, 1994,
p. 173) $^{1}$

1 Todas as citações cuja edição se encontra em língua estrangeira foram traduzidas pela autora.
Nesse trecho o termo allgemeine pode ser traduzido por "geral" ou "comum a todos", fato que confere uma ampliação da trajetória encontrada na experiência individual de amor à mãe e sentimentos ambivalentes frente ao pai. Tal afirmação está inserida em um momento do pensamento freudiano de grande transformação: por não mais acreditar em sua paciente neurótica, Freud teria esvaziado a hipótese da sedução real dos pais sobre os filhos, transferindo esta sedução para o cenário da fantasia inconsciente e infantil, criação psíquica comum a todos: os desejos de incesto e de parricídio passaram a ser teorizados como presentes no imaginário de toda e qualquer criança.

Tais pensamentos vão culminar na tese filogenética que aparece em "Totem e tabu" (1913), teoria segundo a qual haveria uma projeção mítica quanto à "origem" da sociedade, da moral e da religião que estaria de acordo com os desejos infantis e os mecanismos de repressão próprios desta generalização da descoberta edípica. Por meio da inferência de Darwin segundo a qual o ser humano primitivo teria vivido em hordas, são-nos apresentadas algumas pressuposições de como teria sido a horda primeva: resumidamente, o pai da horda, como macho-chefe, exercia uma arbitrariedade ilimitada relativamente a todos os integrantes do grupo, conservando exclusivamente junto a si as mulheres do clã. No entanto, um dia, os demais machos da família (tidos como irmãos entre si, já que filhos em torno do pai) que queriam, eles também, desfrutar sexualmente das fêmeas, aliaram-se e juntos mataram o pai, pondo fim à horda paterna. Unidos, eles deram início ao primeiro banquete da humanidade, comendo a carne do pai assassinado, identificando-se com ele ao devorarem seu corpo, apropriando-se da sua força.

Entretanto, após essa festa dos irmãos da horda em que se celebrou o ódio ao pai e sua eliminação, sentimentos ternos quanto ao morto surgiram nos assassinos. Essa ambivalência 
sentimental em relação ao pai da horda trouxe o arrependimento de seu assassinato pelos filhos. Teria sido esse arrependimento o motor para a instauração da sociedade e que teria motivado a criação da consciência por identificação com o pai morto, bem como a inauguração do sentimento de culpa, sentimento este que teria instituído a moralidade e a civilização. Assim, exibe-se a obediência a posteriori às imposições do pai, de forma que o pai morto de certa maneira, permanecera vivo por meio da transformação de suas imposições em leis imputadas coletivamente e aceitas socialmente. Assim, "todos renunciam a tomar o lugar do pai, ou seja, o lugar da Lei" (GABBI JR, 1993, p. 12), de modo que, "o poder [do pai] não foi desmitificado nem mesmo socializado, pelo contrário, ele se tornou sagrado e, enquanto tal, seu aspecto fascinante perdura e se amplifica." (ENRIQUEZ, 1990, pp.33-34) Assistimos, com isso, à sacralização do poder e à permanência, ao menos como espectro moral ou como espírito das leis, do pai primevo.

A aproximação feita por Freud entre o Édipo individual e esta teoria edípica social de "Totem e tabu" trouxe a possibilidade de averiguar a existência das mesmas disposições em cada indivíduo, citemos Freud:

posto que todos os seres humanos, em sua primeira infância, vivenciam mais ou menos o mesmo, também reagem frente a isso de maneira uniforme, e poderse-ia engendrar a dúvida se estas reações, junto com suas diferenças individuais, não deveriam imputar-se à herança arcaica (FREUD, 2001, p. 94-95)

Isso quer dizer que, frente à situação edípica que lhe é apresentada pela constituição familiar, a criança tende a reagir conforme ao modelo filogenético herdado através das gerações, não se atendo de maneira estrita somente à realidade do que foi experienciado por si mesmo. Assim, podemos dizer que a experiência edípica é entendida por Freud como necessária e inescapável, uma vez que todo ser humano já foi um bebê carente de ajuda e segurança, havendo sentimentos ambivalentes em relação aos que cuidaram de si, o que já seria suficiente para a instauração do complexo de Édipo e para a ativação de tais disposições filogeneticamente adquiridas. Desta forma, cada um dos indivíduos se encontra na situação edípica formando fantasias originárias (Urphantasien) de incesto e de parricídio.

Por consequência, podemos igualmente dizer que a moralidade formada através da experiência edípica e cristalizada na 
instância do Super-eu também seria válida de forma geral. Por isso, delimita-se um modo específico de submissão de todos os indivíduos à lei (seja ela a lei filogenética do pai morto na horda ou a do Super-eu individual), uma vez que esta autoridade "transcende" a ordem do empírico, apresentando-se como um espectro "de um pai situado fora do tempo, pai que se faz um com a impossibilidade e a eternidade presumida da lei." (SCHNEIDER, 1994, p. 82) Com isso, a inconsciência da fantasia da autoridade pode se generalizar enquanto mítica e impossível de seguir. Neste sentido, citando David-Ménard, se "toda proposição universal afirmativa, e em particular aquela que enuncia a submissão de todos os homens à lei, supõe o recalque [...] daquele que anuncia a lei e que é exceção nisso" (DAVID-MÉNARD, 2009, p. 52), então é a "transcendência" mítica em torno do portador da lei moral que permite sua generalização, já que nenhuma pessoa empírica pode portá-la, mas todos devem estar sob seu jugo.

Assim, por meio deste esquema edípico, todo indivíduo moral se constitui através de uma dívida genealógica impossível de cumprir, diante da qual há incumbências de uma tarefa passada, um engajamento que visa uma autoridade "transcendente" e que jamais está completamente presente, mas que, mesmo assim, exige uma fidelidade geracional. A constituição de si mesclada à perpetuação dos ancestrais impõe que "o sujeito se assuma culpado do que 'aconteceu' antes mesmo que ele tenha experiência de ser o herdeiro disto" (ARAMBOUROUMÉLÈSE, 2009, p. 189). Neste sentido, podemos dizer que a moral do Super-eu, uma vez proveniente do complexo de Édipo, pode ser compreendida como um aspecto inescapável para os indivíduos da cultura, ganhando ares de repetição necessária e, com isso, de determinação social.

No entanto, é justamente contra esta generalização moral e edípica presente na teoria freudiana que o caso donjuanesco se apresenta. Lembremos como no texto "A sombra de Don Juan" de Renato Mezan estão figurados os vários sentidos da palavra sedução: entendida como desencaminhar, enganar ardilosamente e desonrar, tais denominações da sedução configuram a visão ética da figura de exceção à lei moral e aos costumes que Don Juan representa. Este conquistador escapa à regra do mundo patriarcal, questionando os desígnios matrimoniais de honra familiar. Rebelde à autoridade, ele profana os preceitos morais transmitidos através das gerações, de forma que "o crime do filho projeta uma tarefa sobre aqueles que o precederam" (ARAMBOUROU-MÉLÈSE, 
2009, p. 100), tarefa esta de reescrever sua história a partir das experiências de sua própria vida, mas não a partir de dados herdados e pré-determinados por gerações passadas. Ao seduzir sem cumprir os ditames fornecidos socialmente, Don Juan mostra a falta de reconhecimento e pertencimento a uma determinada esfera da cultura e dos costumes sociais, transgredindo a herança e impossibilitando o prosseguimento da filiação familiar. Nas palavras de Schneider, "a questão cai no nível da herança, instalada entre a filiação oficial, edipiana, e uma filiação clandestina, subterrânea, aquela pela qual Don Juan agiria pela sombra." (SCHNEIDER, 1994, p. 23) Assim,

\begin{abstract}
contrariamente à extrema concentração sobre a figura do pai originário, concentração que caracterizaria a trajetória do Édipo e de Hamlet, assiste-se, em Don Juan, a aparição de um personagem [...] que acaba com a visão monolítica do Ancestral. (SCHNEIDER, 1994, p. 85)
\end{abstract}

Deste modo, o assassinato do Comendador representaria simbolicamente como Don Juan exerce a legitimação da singularidade própria ao transgredir a lei do outro. Como uma forma de questionar Freud em sua generalização edípica como uma experiência vivida por todos, este modelo é denunciado em sua impossibilidade de realização singular de uma trajetória de vivida ancorada somente em si mesmo. A possessão da própria história por Don Juan pode ser descrita da seguinte forma, como testemunha Arambourou:

Ao invariante de um mal-estar na civilização que Freud
formulava no começo do século XX, as figuras de Don
Juan opõem as variações singulares de jovens homens
confrontados, em sua aspiração a uma identidade não
alienada, às formas múltiplas que se dão os grupos
humanos para garantir sua permanência. Após a
descoberta freudiana, estas variações não poderiam ser
olhadas sem levar em conta aquelas relações entre os
sexos e a origem da geração [...] e que recebem como
resposta a repressão sob o nome da imóvel referência ao
assassinato do Pai. (ARAMBOUROU-MÉLĖSE, 2009,
pp. 15-6)

Como uma crítica à perpetuação de preconceitos sociais por parte da psicanálise freudiana, Don Juan figura como aquele que não leva em conta nem a dívida ancestral e os determinantes do passado, muito menos um cálculo planificado contra danos futuros, portando-se contrariamente ao princípio de realidade 


\section{adenows \\ ESPUC \\ BELO HORIZONTE - N. 28 - 2016}

freudiano:

Don Juan é a figura eterna de um Eros desencarnado, pura potência de ato que se alimenta dos obstáculos que encontra $[\ldots]$, ele não encontrou os caminhos de realização que ultrapassam o próprio instante do ato. Viver é sua obra única, uma "instalação" em perpétuo perigo de colapso. (ARAMBOUROU-MÉLÈSE, 2009, p. 195)

Portando-se exclusivamente conforme o princípio do prazer por não levar em conta um cálculo para evitar sofrimentos futuros, ou ainda sem a memória de um tempo passado, podemos dizer que o confronto de Édipo com Don Juan se trata, sobretudo, do lugar da culpa diante de uma dívida genealógica edípica, culpa originária ligada ao assassinato do pai primevo, culpa individual e inconsciente diante do desejo fantasioso edípico existente em cada um, culpa que Don Juan se recusa a assumir. De certa forma, a culpa pode ser entendida como uma ligação simbólica que assegura a linhagem e o pertencimento social e cultural, culpa que exige ser reconhecida e inscrita. Por isso, Don Juan pode ser interpretado como a figura que exibe socialmente a resolução de um conflito interno existente em cada ser humano entre desejos e repressões, ou ainda, entre alienação e o que podemos entender como uma certa liberdade de fazer sua própria história.

Como exemplificação de nossa análise comparativa, lembremos de mais alguns aspectos existentes entre a noção filogenética freudiana de "Totem e tabu" e a história donjuanesca. Atentemos à realização do mítico banquete totêmico - quando os filhos da horda primeva comem a carne do pai morto. Na sequência desta festa totêmica, no entanto, o pai morto continua a assombrar os filhos vivos, uma vez que suas leis continuam em vigor mesmo após a sua morte, tornando-se uma transcendência responsável pela inauguração da sociedade organizada por leis, religião e moral, tal qual figurado pela teoria do Édipo social. Já no caso de Don Juan, ocorre o jantar de morte diante da estátua do Comendador como portador da lei, figura de autoridade cujo fantasma vingativo levará o sedutor para o Além.

Neste paralelo, Freud tende a tornar imóvel a relevância da figura do pai como portador da lei e como voz que dita os costumes e valores morais. É na tentativa de destruir esta regra transcendente aos seres humanos que a figura de Don Juan ganha importância, cuja vitalidade transgressiva desafia não somente o Comendador enquanto vivo, mas também seu 
espírito. Contudo, a figura singular do jovem sedutor deve ser eliminada para que a realização da herança edípica prossiga entre as gerações.

Na lembrança do mito de Édipo como tragédia, o destino pulsional da repetição que impede renovações se aproxima do destino do próprio Don Juan, cuja originalidade e invenção da própria trajetória em relação aos ditames sociais lhe custou a própria vida. A exigência da lembrança do assassinato do pai que permanece vivo como espírito da lei se aproxima da vingança do espírito da lei da figura do Comendador, que, apesar de morto, reintroduz a ordem da dívida, da culpa, da justiça edípica. Esta repetição do esquema edípico como regra, que impossibilita desvios e diferenciações sociais, encontra-se ligada à noção de pulsão de morte, justamente a morte que encontrou Don Juan ao fim de sua trajetória.

O sacrifício do indivíduo inventivo face à repetição está relacionado à intolerância da exceção à regra sem punição exemplar, pois, em caso contrário, todos infringiriam a lei edípica, já que, segundo Freud, o desejo de parricídio e incesto permanece vivo - ao menos no inconsciente - de cada um. Assim, "Don Juan perde toda a humanidade, até a possibilidade de receber uma sepultura." (ARAMBOUROU-MÉLÈSE, 2009, p. 102). Don Juan queria celebrar mais uma vez, como em "Totem e tabu", a morte da lei restritiva, com o banquete sobre a lápide do comendador, assim como os filhos do pai primevo celebraram com uma ceia o assassinato cometido. Ao recusar o papel da memória na sua estruturação de vida, Don Juan perde a batalha final para a petrificação do passado, erigido por Molière, sob a forma de uma estátua diante de um túmulo.

O que se questiona, ao fim da história de Don Juan, é como Freud dificulta, ao seguirmos a sua teoria, a invenção individual diante da lei edípica generalizada e inescapável, ligada a uma situação de morte e culpa. Será que, como diz Schneider, finalmente, "Freud não se fecha [...] a uma fidelidade ao pai morto? Ele se mostra a serviço de uma verdade situada essencialmente no passado colocando a memória como função psíquica privilegiada, como agente de um culto ao pai morto." (SCHNEIDER, 1994, p. 23) Será, então, que aos psicanalistas cabe a função de serem somente os guardiões de uma memória circunscrita à repetição de um passado em forma de fantasma já morto e petrificado? Apesar do presente texto, não achamos que a psicanálise freudiana se interrompa nesta análise, afinal, sua teoria não trata somente de pulsão de morte: há ainda o 


\begin{abstract}
Following up a discussion that develops the theme of Don Juanism together with the psychoanalytic reading, we propose a link between literature and Freud's psychoanalytic concepts, bringing a confrontation between the Oedipus Complex Theory and the play Don Juan (Molière's version). The main objective of our text is to address the issue of generational inheritance since Freud's phylogenesis and social theory, as mechanisms that make the Oedipal law general and inescapable. Don Juan appears opposed to family and cultural affiliations: he is the model of a seducer who denies the social determinants related to his father's imperatives. He represents a chance to bring up the debate on the natural formation of a life trajectory connected to the fulfillment of wishes in relation to his objects of love, a motive that leads us to some questions about belonging, recognition, transgression, autonomy and the absence of guilt. It is in this context that we will also make a parallel between the mythical banquet of "Totem and Taboo" and Don Juan's death dinner with the statue of the Commander, whose ghost will lead Don Juan to the Other World. Going beyond the specific characteristics that such banquets mean in their own contexts, we understand that both share a common background, namely the repetition of the law that is required by a kind of "transcendence" of the ghost that determines the singular trajectories, a repetition that is related to the notion of Freudian death drive.
\end{abstract}

Keywords: Law. Oedipus. Inheritance. Singularity. Ghost. 


\section{REFERÊNCIAS}

ARAMBOUROU-MÉLÈSE, Miren. Les héritiers de Don Juan - déconstruire la transmission coupable. Paris: Campagne Première, 2009.

COSTA, Virginia Helena Ferreira da. Aspectos das relações interpessoais em Freud: questionamentos morais. $150 \mathrm{f}$. Dissertação (Mestrado em Filosofia) - Faculdade de Filosofia, Letras e Ciências Humanas, Universidade de São Paulo, São Paulo, 2014.

DAVID-MÉNARD, Monique. Les constructions de l'universel - psychanalyse et philosophie. Paris: Quadrige/PUF, 2009.

ENRIQUEZ, E. Da horda ao estado - psicanálise do vínculo social. Rio de Janeiro: Jorge Zahar, 1990.

FREUD, Sigmund. Moisés y la religión monoteísta. In: FREUD, Sigmund. Obras completas volumen 23. Argentina: Amorrortu Editores, 2001. p. 1-132.

FREUD, Sigmund. O inquietante. In: FREUD, Sigmund. História de uma neurose infantil : (o homem dos lobos) ; além do princípio do prazer e outros textos (1917-1920). $1^{\mathrm{a}}$ edição. São Paulo: Companhia das Letras, 2010a. p 328-376.

FREUD, Sigmund. Os instintos e seus destinos. In: FREUD, Sigmund. Introdução ao narcisismo, ensaios de metapsicologia e outros textos (1914-1916). São Paulo: Companhia das Letras, 2010b. p. 51-81.

FREUD, Sigmund. Tótem y tabú. Algunas concordancias en la vida anímica de los salvajes y de los neuróticos. In: FREUD, Sigmund. Obras completas volumen 13. Argentina: Amorrortu editores, 2000. p. 1-164.

GABBI JR, Osmyr Faria. A teoria do inconsciente como teoria da memória. Revista da psicologia USP, São Paulo, v. 4, n. 1/2, p. 247-260, 1993.

MOLIÈRE. Dom Juan ou le festin de pierre. Paris: Classiques Larousse, 1991.

SCHNEIDER, Monique. Don Juan et le procès de la séduction. França: Aubier, 1994.

Recebido em: 26/06/2015

Aceito em: 23/11/2015 